\title{
Performance Measurment and Lead-Time Reduction in EPC Project-Based Organizations: A Mathematical Modeling Approach
}

\author{
Matina Ghasemi $\mathbb{D}^{1},{ }^{1}$ Mazyar Ghadiri Nejad $\mathbb{D}^{2},{ }^{2}$ Naif Alsaadi, ${ }^{3}$ Mu'tasim Abdel-Jaber, ${ }^{4}$ \\ Mohd Shukri Ab Yajid, ${ }^{5}$ and Mamun Habib $\mathbb{1}^{6}$ \\ ${ }^{1}$ Business Department Faculty of Business and Economics, Girne American University, Via Mersin 10, Kyrenia 99428, \\ TRNC, Turkey \\ ${ }^{2}$ Industrial Engineering Department, Girne American University, Via Mersin 10, Kyrenia 99428, TRNC, Turkey \\ ${ }^{3}$ Industrial Engineering Department Faculty of Engineering Rabigh Branch, King Abdulaziz University, Jeddah 21589, \\ Saudi Arabia \\ ${ }^{4}$ Department of Civil Engineering, Al-Ahliyya Amman University, Amman, Jordan \\ ${ }^{5}$ Management \& Science University, Shah Alam, Selangorm, Malaysia \\ ${ }^{6}$ School of Business and Entrepreneurship, Independent University, Dhaka, Bangladesh
}

Correspondence should be addressed to Mamun Habib; mohammad.habib@uta.edu

Received 4 October 2021; Revised 9 December 2021; Accepted 15 January 2022; Published 22 February 2022

Academic Editor: Alireza Goli

Copyright (c) 2022 Matina Ghasemi et al. This is an open access article distributed under the Creative Commons Attribution License, which permits unrestricted use, distribution, and reproduction in any medium, provided the original work is properly cited.

\begin{abstract}
To characterize the process of lead-time reduction in EPC project-based organizations, including the engineering, procurement, and construction activities, various elements such as organizational issues, firm resources, used methods and techniques, and performance measuring tools are important. In this study, the four mentioned elements are evaluated through a survey in different EPC project-based organizations. The survey is sent to only experts and managers who are involved in EPC projects, and the obtained data is used to test the relationship between the mentioned variables and the lead time of developing new products. This evaluation is followed by a set of generalized lessons learned and courses of action to improve the development process. Additionally, the attributes of performance measurement in such projects are scrutinized. Therefore, to analyze the impacts of the mentioned variables and their variations on the performance measurement, a mathematical model based on the fuzzy approach is developed. The results show that all of the four considered variables are correlated to the lead time and affect the quality perceived by the main client and the cost of the project. Moreover, data obtained from the proposed mathematical formulations illustrated that the fuzzy modeling approach is an effective method to predict the performance measurement level when the levels of the input variables are given.
\end{abstract}

\section{Introduction}

In today's economic world, most organizations are looking to find the factors that create competitive advantages regarding the new product development (NPD) [1]. The development of new products helps organizations to maintain their competitive and monopoly position in the market. Introducing the development of new products' strategies, models, and processes plays a crucial role for all types of organizations and their long-term survival [2-4].
Competitive markets force small- and medium-sized enterprises (SMEs) to move and improve themselves from the designing process to the engineering one. Therefore, SMEs that can fulfill the customer needs regarding features and quality of products can successfully enter the global market. The phrase "Customer is the king" indicates how much customer needs are important and how much their needs change over the time. This shows that only companies that offer the right products, at the right time and with the right price, can expect success in the market. Naturally, any 
product that does not meet the needs of customers, or since it is expensive or is produced and delivered after the deadline and so forth, cannot be successful [5-7]. The only way to reduce production's lead time is to coordinate all stages of development. By analyzing the stages of the NPD process, the volume and content of product development activities may be controlled, considering the quantity and production objectives. Consequently, such considerations make significant differences between NPD activities on the scale of individual or mass production [8-10].

Competitions for faster launching new products in the market have forced companies to discover effective ways to minimize the lead time of new products. Several methods have already been suggested in the literature to decrease the lead time of NPDs [11-13]. One of the strategic approaches which are used to boost the variety of products and to speed up the NPD process is product modularity. This approach standardizes product components that can be shared and reused in a range of products and is launched frequently and easily by modifying and combining different qualified modules from the existing designs. Therefore, different teams can design and test modules and reduce the time of product design simultaneously. Despite convincing evidence of potential benefits in reducing NPD lead time, very few empirical studies confirm its effect on NPD performance. Studies show that there is a positive relationship between the modularity of products and their strategic flexibility [14-16]. Product modularity affects several dimensions of competitive performance, such as product costs, quality, flexibility, and manufacturing cycle time [17-21].

The motivation for rapid product development is different according to the aims of companies. It is important to identify why a company wants to accelerate the process, as the reason verifies which rules and tools should be used and how they should be implemented. This research focuses on the elements that may have the biggest effect in attaining speed and flexibility in NPD. Moreover, the four main perspectives, which we believe could lead to a reduction in NPD time, are discussed in detail. Given the framework defined above, there are two major objectives [22-24]. The first one is to characterize the process of reducing the lead time in NPD, and the second one is to identify and evaluate the issues that facilitate the process for performance measurement in EPC organizations [25].

The current study, by considering four main indicators in new product development, organizational issues, firm resources, used methods and techniques, and performance measuring tools and their main subfactors, aims to find the correlation among each of the factors and the time reduction. Moreover, a mathematical model based on fuzzy logic modeling is introduced to predict the performance measurement level, based on its subfactor impacts.

This study is continued by revising the related literature in the next chapter. Chapter 3 contains the research methodology including data collection and the proposed mathematical model. The results of both data analysis and fuzzy logic results are provided in Chapter 4. Chapter 5 contains the discussions, and, finally, the study is concluded in Chapter 6.

\section{Literature Review}

Success in launching a new product is an important issue for business owners and managers. Additionally, this issue has a special complexity, as determining the factors affecting the successful development of a new product in different studies has different results. One of the reasons is related to characteristics of the company such as technology, structure, and size $[3,26]$.

From a broader perspective, a new product development strategy is an important factor in a country's economic wealth. Unfortunately, the importance level of new product development is not commensurate with the level of success, while the risk of failure in the new product development strategy is very high $[27,28]$. Although the failure rate of new product developments is known in various studies, scientists have warned that the percentage of failure of new products is still worrying. Therefore, researchers try to provide a prescriptive theory to guide the best practical context of a new product development strategy to achieve success. The successes are categorized as empirical and theoretical perspectives, which ultimately lead to the identification and study of various factors of success in the new product development strategy $[29,30]$. Hence, the following concepts should be considered in new product development strategies.

2.1. Nonstop Need for New Products. Intense global competition, rapid shifting of customers' needs, and increasing the rate of their sophistication, besides the technological improvements, force firms to develop new products endlessly. The business press constantly addresses the failure of NPD processes within the firms in responding to market changes, while it seems that their new products have the potential to be successful [31]. So, what are the problems that look common in many well-established firms?

2.2. New Product Strategy. Product development faces big challenges and intense competition in today's fast environmental changes. In other words, attention has turned toward rapid NPD, in which cost and quality are among the main prerequisites. So far, taking all the arguments into account, there is no doubt that speed and flexibility in product developments are the main indicators that determine which companies could meet this sustainable competitive advantage [32].

2.3. Cycle Time Reduction. The lead-time reduction can be another goal, besides the profit and market share. However, the lead-time reduction cannot be attained without organizational change. According to Goldt [33], there are some managerial issues related to the lead-time reduction debate:

(1) Concentration on the process rather than personal level: This detachment of the personal level permits individuals to look for the root cause of the problems within the process. 
(2) Evaluation of tasks based on the created value for external customers: this means that when the staff of a company is expected to meet the needs of internal customers, such as top managers, they tend to focus on partial optimization of a department instead of creating value for the whole system. This causes a general lack of quality, which contradicts the philosophy of reducing lead time.

(3) Integration and management of required information: a particular group keeps information within the organization and it causes a delay in the decisionmaking process. Organizations should provide an open integrated information flow while considering recently raised values of knowledge management and security issues. In other words, the required information should be received at the right time, in right place, and in the right format [34].

(4) To create a shared goal and a common sense within the different functional areas: according to the initial principles of concurrent engineering, individuals within a team view the same problem from different perspectives. Therefore, the trade-offs must be resolved based on the merits of the ideas, not the individuals. Consequently, few spaces within different functions remain unviewed by the personnel [35].

(5) Knowledge and nonmanufacturing resources should be added: to improve the process, besides design, tools, and techniques, the knowledge, information, and other nonmanufacturing resources should be considered, which need continuous attention and commitment of the individuals $[36,37]$.

(6) Cost of delay should be included in trade-off analysis: to have more sophisticated decision-making, the cost of delay should be considered as well. Every particular product has an ending point considering its market demand. The later introduction of products is, the less market share could be achieved by the firm and vice versa [38].

(7) Bottleneck management should be applied for NPD: Surplus capabilities and facilities in terms of human resources, engineering techniques, and so forth should be presented to avoid bottlenecks in NPDs. Especially in a learning organization, dependency on bottlenecks should be reduced in favor of process improvement and lead-time reduction. Moreover, such tools should provide a transparent image of the bottleneck, which provides better utilization of nonconstrained resources [39]. To have high efficiency in this field, it is required to make a balance between resource utilization and bottlenecks. Although various factors help to achieve this harmony, planning tools as well as MES is needed for achieving the goal.

(8) Sometimes a common misunderstanding according to the lead-time reduction is realized by concerns about working faster and harder in longer hours.
Likewise, utilizing the latest technologies and automation systems is not the principal objective of lead-time reduction [40]. The lead-time reduction is a nonstop journey with the objective of continuous learning and commitment, dedicated to the improvement of the process and knowledge of the workers.

(9) A conflicting set of management demands on the NPD lead-time reduction should be met: time, cost, and quality are internally interconnected, and just optimizing all of them can create a market value. The NPD should fulfill three distinctive inputs: right quality product, right time, and acceptable cost $[14,41]$.

The lead-time reduction may be considered as an umbrella that is integrated with cost and quality. In other terms, the lead-time reduction acts as a cover, where cost and quality could be progressed underneath. Regarding the main indicators of time reduction in EPC organizations, after conducting interviews with some directing managers of the companies in this study, the four levels are investigated as organizational issues, process attributes for design methods and techniques, company resources issues, and performance measuring tools. Each of the mentioned levels is explained in the following.

2.3.1. Organizational Issues. According to the literature, many researchers have studied organizational issues in NPD and considered various attributes in this area [42-44]. Considering the studies in the literature and the interviews with the managers, thirteen attributes and their related measurements are considered in this study to deal with the organizational issues. These attributes are projectization, team empowerment, cross-functionality, rewards and incentives, top management support, hierarchical levels, individuals experience, rapid decision-making, team common sense, number of parallel projects, number of projects per person, project objectives definitions, and change flexibility.

2.3.2. Process Attributes for Design and Manufacturing Methods and Techniques. Similar to the organizational issues, there are various studies related to the process attributes for design and manufacturing methods and techniques in NPD [45-47]. Based on the literature and interviews with the managers, the following attributes and their measurements are considered for this purpose:

(i) CAD/CAM: Computer-aided design (CAD), computer-aided manufacturing (CAM), and computeraided engineering (CAE).

(ii) DFM/DFA: reducing time for entering market while maintaining product quality and functionality results in the introduction of design for manufacturing (DFM), which is the concurrent development of process and product design. Design for assembly (DFA) also plays a major role in the design for manufacturing and assembly (DFMA). It 
is said that DFM and DFA are two sides of the same coin in practice.

(iii) Robust design: according to Thornton et al. [48], robust design is a set of engineering design methods used to create robust products and processes. Likewise, a robust design (or process) performs properly in the presence of noise effects. Noises are due to many kinds of uncontrolled variables that can influence final performance such as temperature and humidity.

(iv) QFD: Quality Function Deployment (QFD) is a procedure-based approach for identifying and formulating the customer needs and converting them into exact criteria and plans to meet the needs. This is called the customer input or the voice of the customer, which is attempted to be captured in various ways such as deep interviews, focus groups, participant observation, field reports, and questionnaires.

2.3.3. Company Resources Issues. For examining the company recourses issues, various elements such as key suppliers, reliance on suppliers, access to reliable suppliers, integration among suppliers, outsourcing, and lead user involvement should be considered.

2.3.4. Performance Measuring Tools. Regarding the performance measuring tools in the NPD, six attributes and their measurements are considered, based on the outcomes of the interviews. These attributes are PERT/CPM, rework, credible schedule, time as a measurement tool, visibility of delay factors, and communication; the latter is related to the management information system (MIS). Note that the critical path method (CPM) and program evaluation and review techniques (PERT) are the two powerful tools that help to schedule and manage complex projects.

\section{Research Methodology}

To find the starting and ending points of the development time and the characteristics of the activities in this research, some Iranian EPC organizations that are involved in national strategic projects are requested to participate. As it has been clarified that the influencing variables, stages, and factors are interconnected to form a development process, considering the four main mentioned perspectives and their related elements, a survey in the form of a questionnaire is designed. The considered respondents must have degrees/ diplomas in engineering, management, or business field and be aged from 30 to 55 years, with at least 5 years of work experience in the EPC organizations. The managers are asked if their organizations evaluate their organizational performance, new product design, development strategies, supplier assessment practices, methods and techniques used in NPD, and performance monitoring and measurement tools. They are asked to reply to the questions using a 6-point Likert scale, where the importance of the various attributes is
1 for extremely low up to 6 for extremely high. A couple of experts and managers are considered for a pretest of the survey to examine the validity of the questionnaire. Then, in case of any clarification, the questions are reworded to improve validity and precision. For those who are enlightened and familiar with the survey structure, just the questionnaire is sent. It is assumed that the repliers are familiar with their organizations' new product design and development practices. An incentive for sending the survey results is provided to encourage them to participate in filling out the surveys precisely. Managers are also asked about the company's abilities related to competitors to minimize the time of the NPD.

3.1. Data Collection. Among the 14 considered companies, 10 could be able to answer the questions free of inaccuracy. An average of four EPC projects per company, during the past three years, have been considered to comply with the survey's objectives, which includes a total number of 40 projects. The mean number of employees in these companies was 46 , including both part-time and full-time staff. The development programs during the past three years have been carried out within the companies. For each attribute that is mentioned in Tables 1, 2, 3, and 4, an appropriate measure is defined to study the level of importance of the attributes in the company and subsequently their effects on the lead time of the development programs. Table 1 shows the attributes and measurements of the organizational issues. Followingly, Tables 2 to 4 contain the attributes and measurements of the process, techniques, and methods, company resources issues, and performance measuring tools, respectively.

3.2. Fuzzy Modeling. In this study, to model the performance measuring (PM), a fuzzy logic model is proposed considering the parameters, that is, PERT/CPM (PE), rework (RE), credible schedule (CS), time as a measuring tool (TM), delay factors visibility (DV), doing things right first (DR), and management information (MI) system. Fuzzy logic which was proposed by Zadeh is used to model uncertain or linguistic variables [49]. Figure 1 shows the developed fuzzy model.

To show a degree for the variables, fuzzy membership functions are used. One of the most important fuzzy membership functions is the triangular, which in this study is used to model the performance measuring parameter. Equation (1) shows the general format of the triangular fuzzy membership function, where $l, m$, and $u$ denote the lowest, the most promising, and largest possible values, respectively.

$$
\mu_{A}(x)= \begin{cases}\frac{(x-l)}{(m-l)}, & l \leq x<m, \\ \frac{(u-x)}{(u-m)}, & m<x \leq u, \\ 0, & \text { otherwise. }\end{cases}
$$


TABle 1: Organizational issues.

\begin{tabular}{lc}
\hline Attribute & Measure (importance of the attribute based on a 6-point Likert scale) \\
\hline Projectization & $1=$ pure functional, $6=$ pure projectization \\
Team empowerment & $1=$ extremely low, $6=$ extremely high \\
Cross-functionality & $1=$ extremely low, $6=$ extremely high \\
Rewards and incentives & $1=$ extremely low, $6=$ extremely high \\
Top management support & $1=$ extremely low, $6=$ extremely high \\
Hierarchical level & $1=$ extremely high hierarchical, $6=$ low hierarchical \\
Individuals experience & $1=$ extremely low, $6=$ extremely high \\
Rapid decision-making & $1=$ extremely low, $6=$ extremely high \\
Team common sense & $1=$ extremely low, $6=$ extremely high \\
Number of parallel projects & $1=$ too many projects, $6=$ just one project \\
Number of projects per person & $1=$ too many projects, $6=$ just one project \\
Project objectives definition & $1=$ extremely low, $6=$ extremely high \\
Change flexibility & $1=$ extremely low, $6=$ extremely high \\
\hline
\end{tabular}

TABLE 2: Process attributes, techniques, and methods.

\begin{tabular}{lc}
\hline Attribute & Measure (importance of the attribute based on a 6-point Likert scale) \\
\hline Simplicity and number of documents & $1=$ extremely low, $6=$ extremely high \\
Standardization & $1=$ extremely low, $6=$ extremely high \\
Project complexity & $1=$ extremely low, $6=$ extremely high \\
Project newness & $1=$ extremely low, $6=$ extremely high \\
Concurrent development & $1=$ extremely low, $6=$ extremely high \\
Easy testability & $1=$ extremely low, $6=$ extremely high \\
CAD/CAM & $1=$ extremely low, $6=$ extremely high \\
DFM/DFA & $1=$ extremely low, $6=$ extremely high \\
Robust design & $1=$ extremely low, $6=$ extremely high \\
QFD & $1=$ extremely low, $6=$ extremely high \\
\hline
\end{tabular}

TABle 3: Company resources issues.

\begin{tabular}{lc}
\hline Attribute & Measure (importance of the attribute based on a 6-point Likert scale) \\
\hline Number of key suppliers & $1=$ too many, $6=$ low number \\
Reliance on suppliers & $1=$ extremely low, $6=$ extremely high \\
Access to reliable suppliers & $1=$ extremely low, $6=$ extremely high \\
Integration among suppliers & $1=$ extremely low, $6=$ extremely high \\
Outsourcing & $1=$ extremely low, $6=$ extremely high \\
Lead user involvement & $1=$ extremely low, $6=$ extremely high \\
\hline
\end{tabular}

TABle 4: Performance measuring tools.

\begin{tabular}{lc}
\hline Attribute & Measure (importance of the attribute based on a 6-point Likert scale) \\
\hline PERT/CPM & $1=$ extremely low, $6=$ extremely high \\
Rework & $1=$ extremely low, $6=$ extremely high \\
Credible schedule & $1=$ extremely low, $6=$ extremely high \\
Time as a measurement tool & $1=$ extremely low, $6=$ extremely high \\
Visibility of delay factors & $1=$ extremely low, $6=$ extremely high \\
Communication (MIS) & $1=$ extremely low, $6=$ extremely high \\
\hline
\end{tabular}

A six-degree function is considered for all the mentioned inputs and the output as shown in Table 5.

For providing the fuzzy model, a fuzzy inference system is used, which is capable of inferring the performance of complex systems from data, without the need for any preceding description of a functional structure. Equation (2) contains the membership functions of all the inputs and the output variables. 


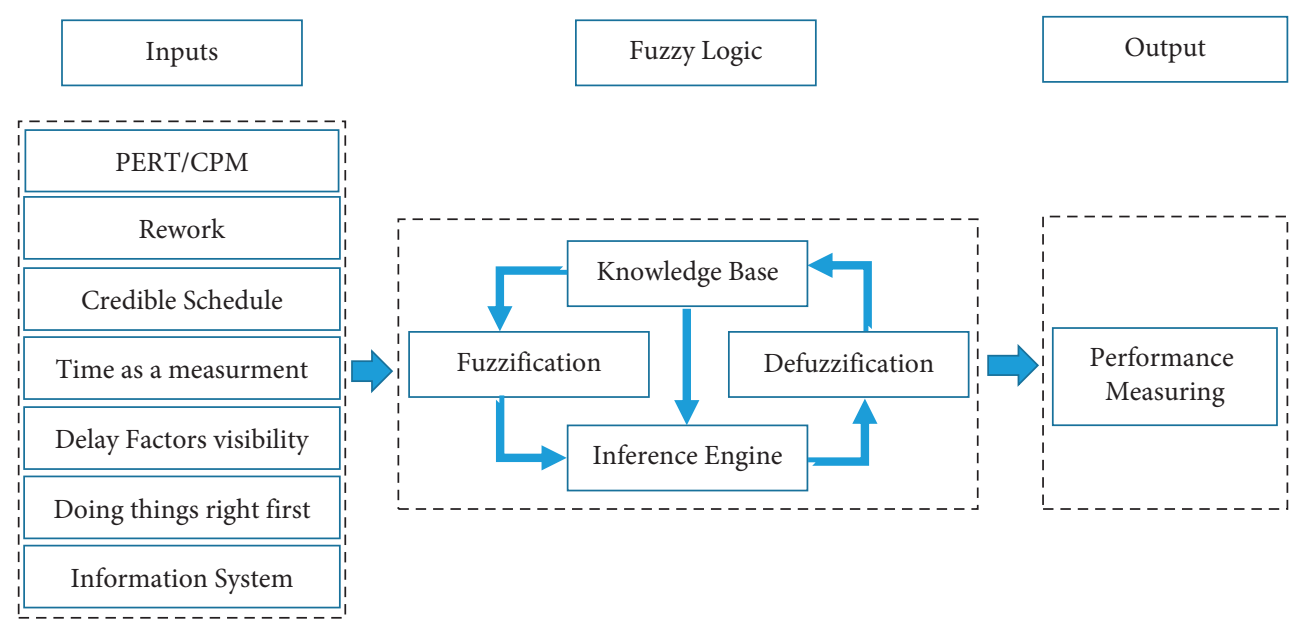

FIGURE 1: Input and output variables of the fuzzy model.

$$
\begin{aligned}
& \mu_{E L}(x)= \begin{cases}1, & x \leq 1 \\
\frac{(2-x)}{(2-1)}, & 1<x \leq 2, \\
0, & \text { otherwise }\end{cases} \\
& \mu_{V L}(x)=\left\{\begin{array}{ll}
\frac{(2-x)}{(2-1)}, & 1<x \leq 2 \\
\frac{(3-x)}{(3-2)}, & 2<x \leq 3 \\
0, & \text { otherwise }
\end{array}\right. \text {, } \\
& \mu_{S L}(x)= \begin{cases}\frac{(3-x)}{(3-2)}, & 2<x \leq 3 \\
\frac{(4-x)}{(4-3)}, & 3<x \leq 4 \\
0, & \text { otherwise }\end{cases} \\
& \mu_{V H}(x)=\left\{\begin{array}{ll}
\frac{(5-x)}{(5-4)}, & 4<x \leq 5 \\
\frac{(6-x)}{(6-5)}, & 5<x \leq 6 \\
0, & \text { otherwise }
\end{array},\right. \\
& \mu_{E H}(x)= \begin{cases}\frac{(6-x)}{(6-5)}, & 5<x \leq 6 \\
1, & x \geq 6 . \\
0, & \text { otherwise }\end{cases}
\end{aligned}
$$

The variations of the inputs and the output parameters and the linguistic values of the experimental design matrix are listed in Tables 6 and 7, respectively.

The considered If-Then rules based on the outcomes from the companies are shown in Table 8.

\section{Results}

4.1. Data Analysis. After collecting the data from the 10 companies that answered the questionnaires without any error, appropriate analysis was performed on the obtained data. Figure 2 shows the correlation between the time and lead user content among the 10 considered firms. Moreover, the regression analysis is illustrated in this figure.

As shown in Figure 2, the more companies tend to develop products on time, the more lead user's content is achieved. Figure 3 illustrates the correlation between the time and cost among the 10 firms. Additionally, the regression analysis is visible in this figure.

As illustrated in Figure 3, the more companies tend to develop the products on time, the more projects will be on a budget. On the other hand, it should be mentioned that emphasizing on only being on a budget could not lead the companies to be on time as well. Figure 4 depicts the correlation and the regression analysis between the time and organizational issues among the companies.

From Figure 4, it is concluded that organizational issues have their effects on shortening development lead time. In other words, the more companies involve elements of the organizational issue in development programs effectively, the more projects tend to be finished sooner or on time. Figure 5 contains the correlation and the regression analysis between the time and progress measure among the companies.

As shown in Figure 5, the progress measuring tools have a direct effect on shortening development lead time. In other words, the more companies make use of measuring tools effectively, the more projects could be developed on time. The correlation and the regression analysis between the time and supplier assessment among the companies are shown in Figure 6. 
TABLE 5: Likert scales of the answers to the questionnaires.

\begin{tabular}{lccccc}
\hline Extremely low & Very low & Somewhat low & Somewhat high & Very high & Extremely high \\
\hline EL & VL & SL & SH & VH & EH \\
1 & 2 & 3 & 4 & 5 & 6 \\
\hline
\end{tabular}

TABle 6: The input and output parameter levels and their values.

\begin{tabular}{|c|c|c|c|c|c|c|c|c|}
\hline \multirow{2}{*}{ Company no. } & \multicolumn{7}{|c|}{ Inputs } & \multirow{2}{*}{$\begin{array}{c}\text { Output } \\
\text { PM }\end{array}$} \\
\hline & $\mathrm{PE}$ & $\mathrm{RE}$ & CS & $\mathrm{TM}$ & DV & DR & MI & \\
\hline 1 & 4 & 3 & 4 & 4 & 4 & 5 & 4 & 4 \\
\hline 2 & 3 & 2 & 3 & 3 & 2 & 3 & 4 & 3 \\
\hline 3 & 2 & 3 & 2 & 2 & 1 & 1 & 2 & 2 \\
\hline 4 & 4 & 3 & 2 & 3 & 3 & 5 & 4 & 3 \\
\hline 5 & 2 & 3 & 2 & 4 & 2 & 3 & 2 & 3 \\
\hline 6 & 3 & 2 & 4 & 3 & 2 & 1 & 2 & 2 \\
\hline 7 & 4 & 5 & 4 & 4 & 4 & 3 & 5 & 4 \\
\hline 8 & 2 & 2 & 1 & 3 & 1 & 1 & 1 & 1 \\
\hline 9 & 3 & 2 & 1 & 2 & 2 & 1 & 1 & 2 \\
\hline 10 & 5 & 6 & 4 & 5 & 4 & 5 & 3 & 5 \\
\hline
\end{tabular}

TABLE 7: Experimental design matrix.

\begin{tabular}{llllllllc}
\hline \multirow{2}{*}{ Company no. } & \multicolumn{9}{c}{ Inputs } & \multicolumn{3}{c}{ Output } \\
& PE & RE & CS & TM & DV & DR & MI & PM \\
\hline 1 & SH & SL & SH & SH & SH & VH & SH & SH \\
2 & SL & VL & SL & SL & VL & SL & SH & SL \\
3 & VL & SL & VL & VL & EL & EL & VL & VL \\
4 & SH & SL & VL & SL & SL & VH & SH & SL \\
5 & VL & SL & VL & SH & VL & SL & VL & SL \\
6 & SL & VL & SH & SL & VL & EL & VL & VL \\
7 & SH & VH & SH & SH & SH & SL & VH & SH \\
8 & VL & VL & EL & SL & EL & EL & EL & EL \\
9 & SL & VL & EL & VL & VL & EL & EL & VL \\
10 & VH & EH & SH & VH & SH & VH & SL & VH \\
\hline
\end{tabular}

From Figure 6, it is concluded that the supplier assessment affects the lead time of the development programs. In other terms, the more companies emphasize suppliers' evaluation, the more projects could have the chance to be finished on time. Similarly, Figure 7 illustrates the correlation and the regression analysis between the time and used techniques.

As may be concluded from Figure 7, the used techniques on the development programs have a direct effect on shortening the lead time of the projects. In other words, the more companies exploit the tools and rules that match their system, the more they can achieve lead-time reduction in their projects.

4.2. Fuzzy Logic Results. The model whose rules are mentioned in Table 8 was solved by MATLAB application according to Figure 8.

Equation (3) is used for defuzzification of the fuzzy number obtained by the proposed model. In this equation, the output, $\mathrm{x}^{*}$ is a fixed and real number, $x_{i}$ gives the central value of every zone, $\mu\left(x_{i}\right)$ is the $i$ th level, and $n$ is the number of rules [50].

$$
x^{*}=\frac{\sum_{i=1}^{n} x_{i} \cdot \mu\left(x_{i}\right)}{\sum_{i=1}^{n} \mu\left(x_{i}\right)}
$$

The experimental results and the predicted values obtained by the fuzzy model are reported in Table 9.

In Table 9, it is seen that all the fuzzy predicted values are exactly equal to the obtained data except for company 8 which is found as 1.32 instead of 1 . The results show that fuzzy modeling is an appropriate method to anticipate the data that are not given previously. Figures 9(a) to 9(h) illustrate the effects of every two mentioned variables on the output which is performance measuring.

Figure 9(a) shows the impact of PERT/CPM (PE) and doing things right first (DR) variables on the performance measuring (PM). It is seen that when the PE variable gets the values in the range of 3 to 5 and DR gets its high values in the range of 4 to 6 , the output variable get the value of 4 , and for other values of these mentioned inputs, the output gets 3.5, which is an average grade. Figure 9(b) illustrates the impact of delay factors visibility (DV) and rework (RE) variables on the performance measuring. The figure shows that when both mentioned inputs are in their lower values, the output variable gets the value of 3 which is less than the average. For the other values of the mentioned inputs, the output value is an average of 3.5 .

Figure $9(\mathrm{c})$ is related to the impact of rework (RE) and doing things right first (DR) variables on the output variable, which is performance measuring (PE). When the DR is in its high values in the range of 4 to 6 and RE is between 2 and 4, the output will be more than average (4). On the other hand, as shown in Figure 9(d), when both input variables of RE and management information (MI) system get high values, the output, PM, is higher than the average. Figure 9(e) shows the impact of the DR and credible schedule (CS) on the PM. This 
TABLE 8: Rules of the proposed fuzzy model.

\begin{tabular}{ll}
\hline Rules & Rule definition \\
\hline 1 & If PE is SH and RE is SL and CS is SH and TM is SH and DV is SH and DR is VH and MI is SH then PM is SH. \\
2 & If PE is SL and RE is VL and CS is SL and TM is SL and DV is VL and DR is SL and MI is SH then PM is SL. \\
3 & If PE is VL and RE is SL and CS is VL and TM is VL and DV is EL and DR is EL and MI is VL then PM is VL. \\
4 & If PE is SH and RE is SL and CS is VL and TM is SL and DV is SL and DR is VH and MI is SH then PM is SL. \\
5 & If PE is VL and RE is SL and CS is VL and TM is SH and DV is VL and DR is SL and MI is VL then PM is SL. \\
6 & If PE is SL and RE is VL and CS is SH and TM is SL and DV is VL and DR is EL and MI is VL then PM is VL. \\
7 & If PE is SH and RE is VH and CS is SH and TM is SH and DV is SH and DR is SL and MI is VH then PM is SH. \\
8 & If PE is VL and RE is VL and CS is EL and TM is SL and DV is EL and DR is EL and MI is EL then PM is EL. \\
9 & If PE is SL and RE is VL and CS is EL and TM is VL and DV is VL and DR is EL and MI is EL then PM is VL. \\
10 & If PE is VH and RE is EH and CS is SH and TM is VH and DV is SH and DR is VH and MI is SL then PM is VH.
\end{tabular}

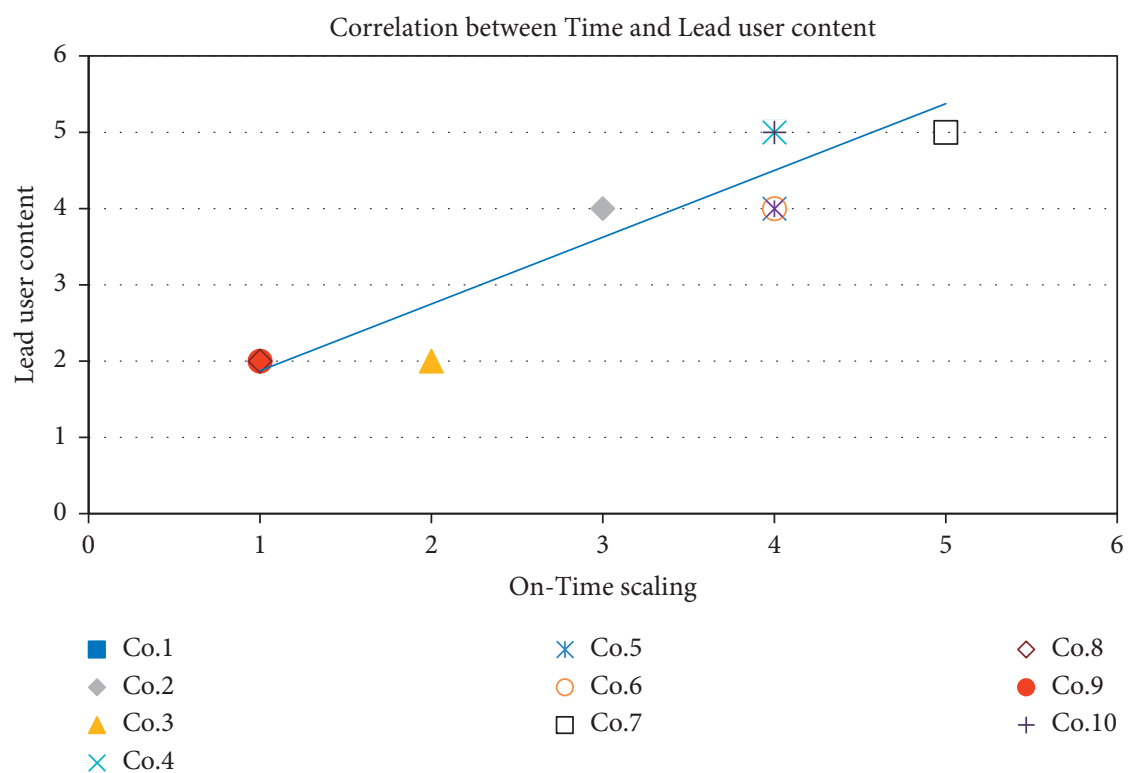

Figure 2: Correlation between the time and lead user content among the firms.

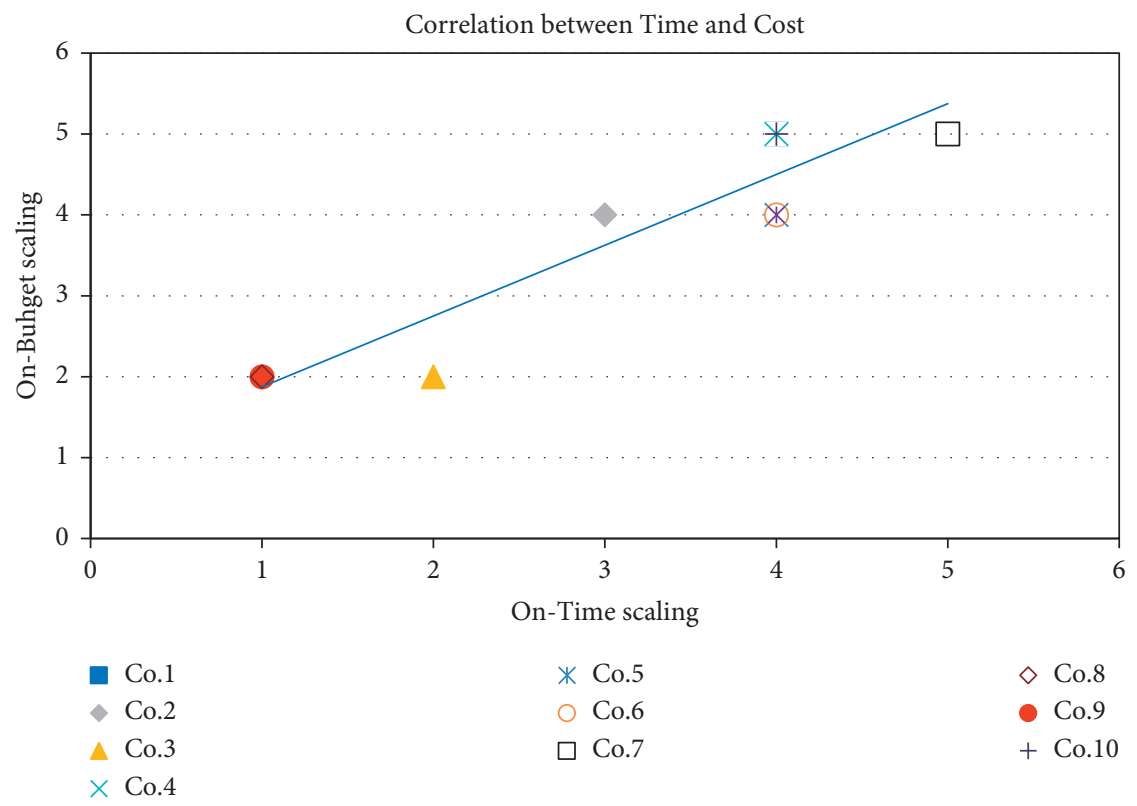

Figure 3: Correlation between the time and cost among the firms. 


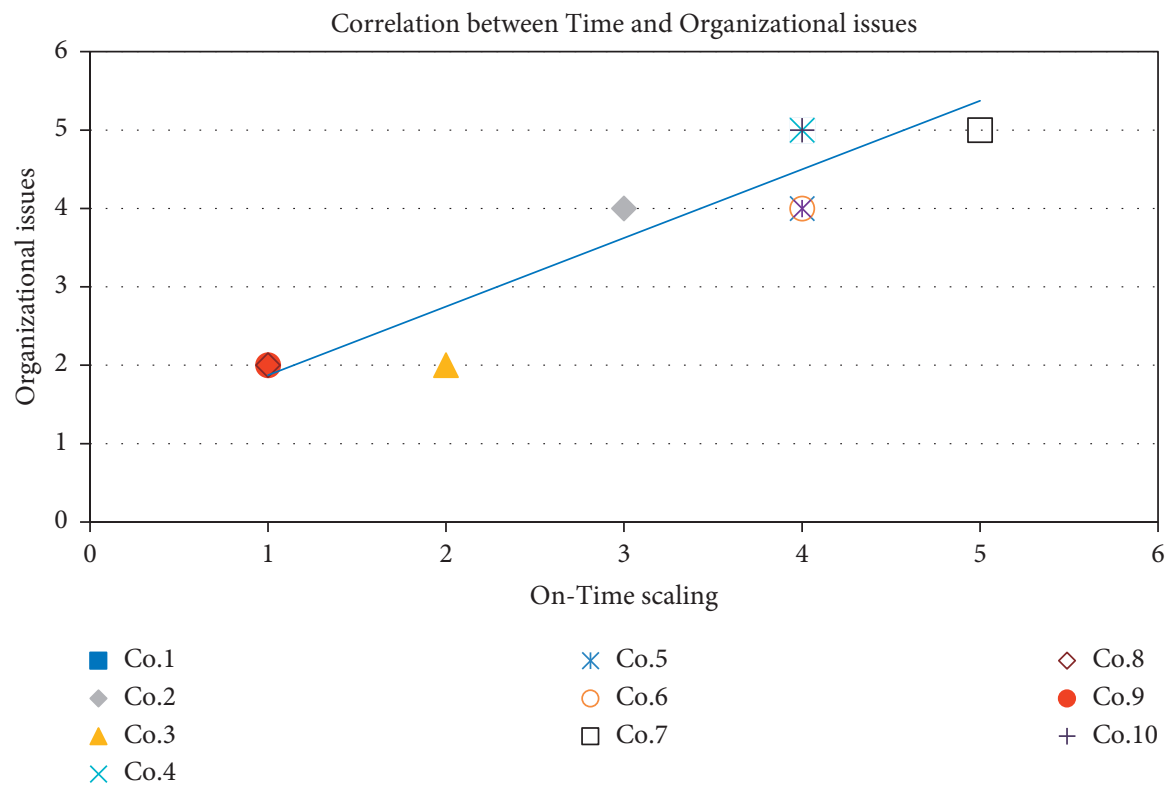

FIGURE 4: Correlation between the time and organizational issues among the firms.

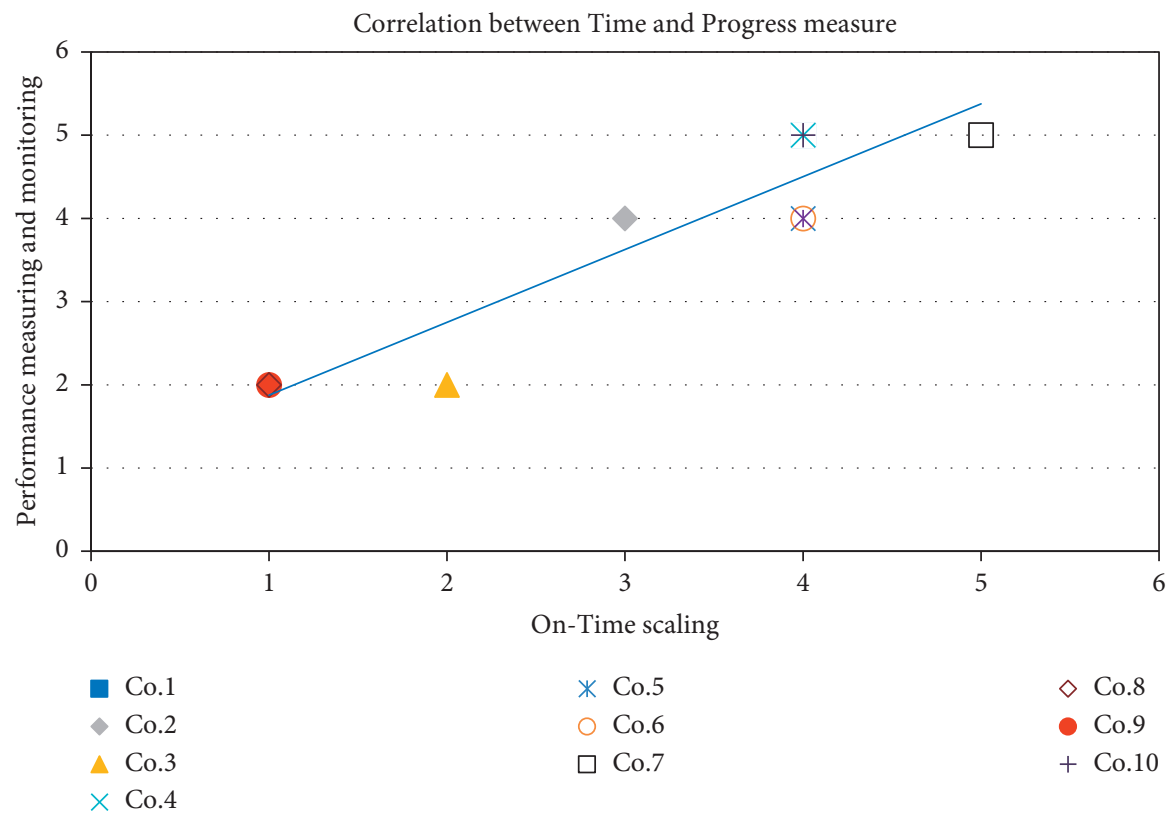

FIGURE 5: Correlation between the time and progress measure among the firms.

figure illustrates that the output variable has the highest sensitivity on the CS when DR has a high value from 4 to 6. When CS has a low value, in the range of 1 to 3 , PM has a low value and when CS gets a high value, in the range of 3 to 5 , PM gets a high value; otherwise, the output parameter has an average value.

The same impact as that in Figure 9(a) can be seen in Figure $9(\mathrm{f})$ just by changing the input variable of performance measuring (PE) to time as a measuring tool (TM). Such an impact can be seen in Figure 9(g) just after substituting TM by delay factors visibility (DV). Finally, Figure 9(h) illustrates the impact of management information (MI) system and doing things right first (DR) on performance measuring (PM). It is displayed that, for the values in the range of 3 to 5 for MI and a high-level value for DR in the range of 4 tp 6 , PM gets a high value of 4 .

\section{Discussion}

Many companies tend to be on budget rather than being on time. They believe that being on a budget is the goal and the other characteristics should be under control. This research shows that although projects tend to be on a budget, lead users' involvement plays a greater role, and, consequently, 


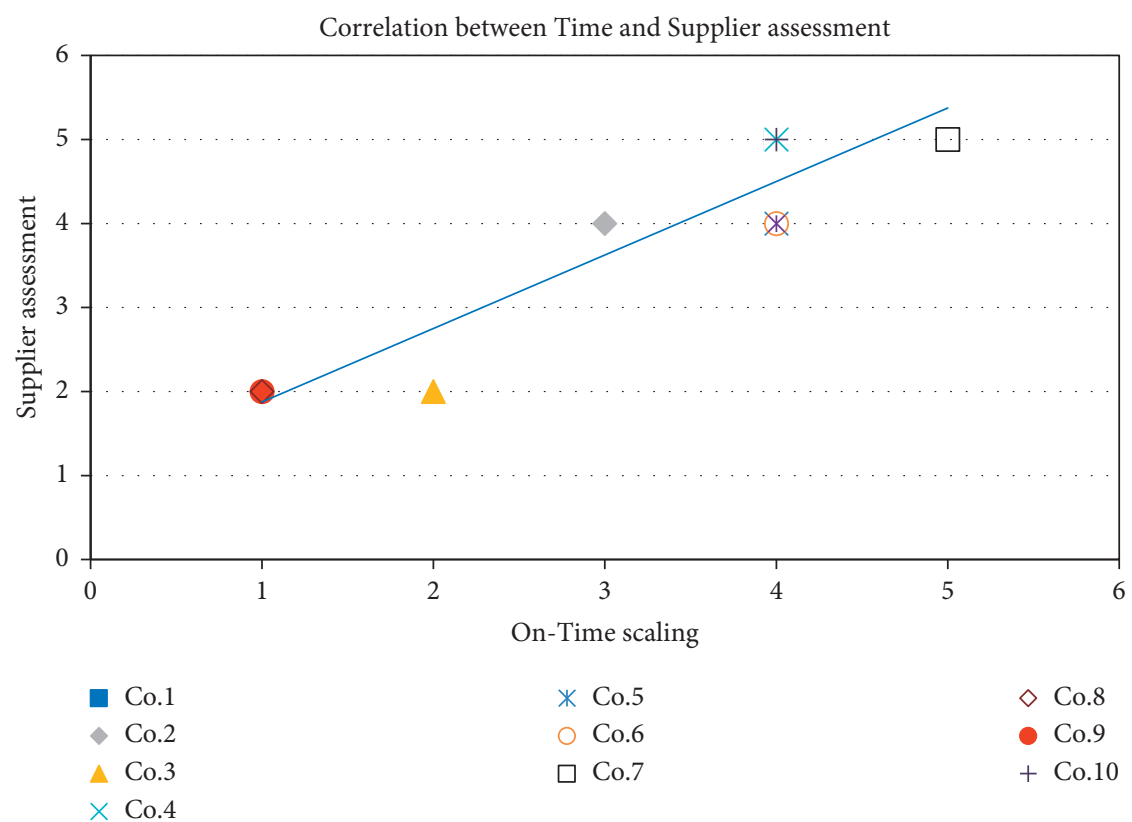

FIgURE 6: Correlation between the time and supplier assessment among the firms.

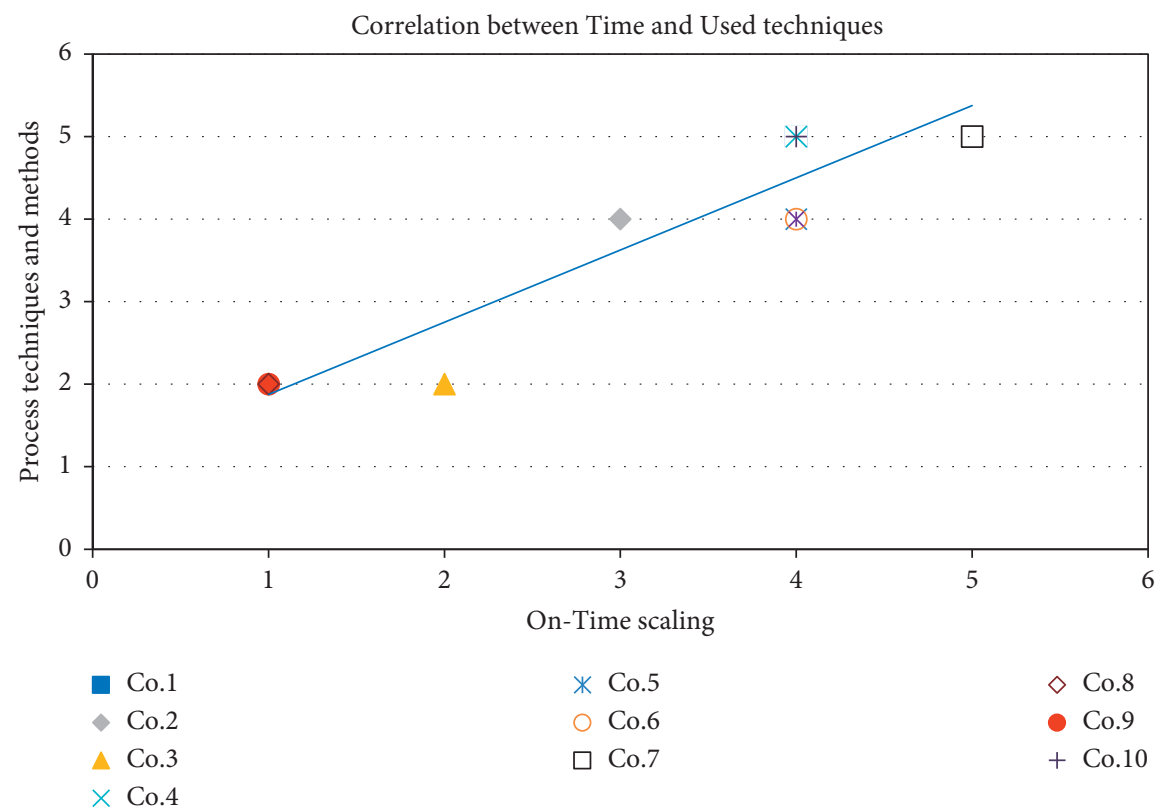

Figure 7: Correlation between the time and used techniques among the firms.

the timing of the project should be as important as being on budget. Perhaps the development programs are carried out on budget nominally, but analyzing the time value of the project reveals the actual cost of the total plan. Moreover, the results illustrated that the extent of lead user content is a good sign of creating real value for the companies. From a strategic point of view, not only is the short-term success of firms declined, but also firms are the victim of their temporary achievements. Creating value is a long-term mission for firms seeking to maximize their wealth. To find where a firm value could be created is the key success of the organization to survive in today's rapid environmental changes. For instance, many successful firms are providing ways for customers to participate as an integral part of development programs.

Companies struggle to define clear objectives and establish common sense, credible schedules, and visibility of delay factors, as all of them are needed for making rich preplanning before the development program begins. A reliable planning and scheduling process could contribute to the timing of a project. In project-based organizations, it is found that although the companies establish the work 

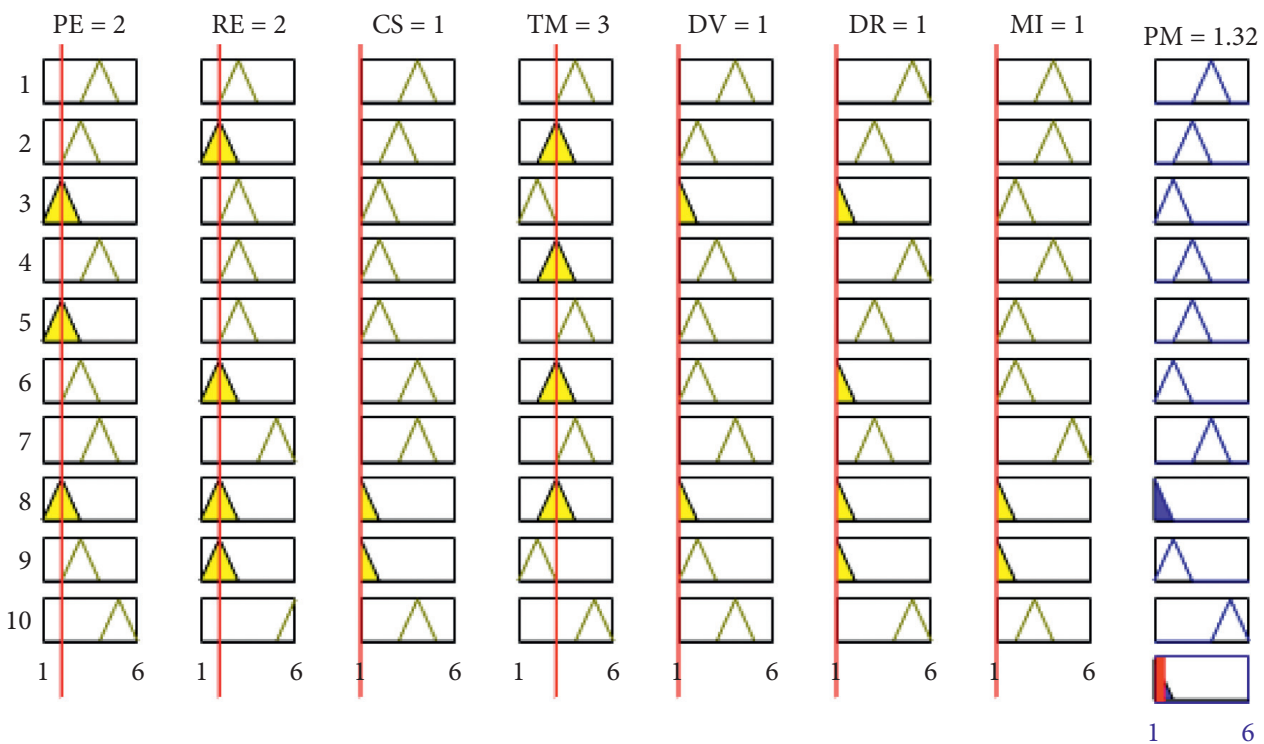

Figure 8: Rules set for the given data.

TABLE 9: The experimental and fuzzy predicted results.

\begin{tabular}{lcc}
\hline Run & Obtained data & Fuzzy predicted results \\
\hline 1 & 4 & 4 \\
2 & 3 & 3 \\
3 & 2 & 2 \\
4 & 3 & 3 \\
5 & 3 & 3 \\
6 & 2 & 2 \\
7 & 4 & 4 \\
8 & 1 & 1.32 \\
9 & 2 & 2 \\
10 & 5 & 5 \\
\hline
\end{tabular}

breakdown structure (WBS), they suffer from a rich project planning wherein the definition of the activities is not identified. In other words, the link between activities and the expected duration to accomplishment is artificial. Each activity needs to be designed in detail, where its inputs and outputs should be defined based on the nature of the activity. This shortcoming results in decreasing the creditability of the schedule and, consequently, the project delay. Although the supplier assessment strategy could not have a straight impact on the product design and development timing, it influences projects through the quality perceived by the lead users. Therefore, product development teams cannot ignore the capability of their suppliers. For instance, the product design team must consider whether their suppliers can provide the required new parts within a reasonable time, at the expected cost, and with the required quality level. On the other hand, when reliable suppliers are involved in the development programs, the project risk is shared. It appears that firms should rate their suppliers based upon their specific needs.

The evaluation of project progress is important in monitoring the achievement of interconnected activities, warning the potential delay problems, the performance of the activities, and the timing of the program. This causes a recovery or improvement action to be proactively taken. On the other hand, poor progress measure results in misleading the evaluation of the project in terms of time, quality, and cost. Likewise, when rework occurs, its potential of shortcomings is added to this imprecision. Project-based organizations pay little attention to the power of communication in their entire systems, where this results in a significant amount of delay in the timing of the development programs.

Various types of information are exchanged in product development including design requirements, decisions, test results, manufacturing issues, and knowledge shared. Perhaps one could say that, in a product development program, information is the main chain that interconnects the mentioned components to each other. With this definition, the significance of correct and updated information is revealed more. Preparing the information at the right time, right place, and right format is the key to enhancing communication. In addition, poor communication cannot discover the potential of rework and delays and allows the proceeding activities to continue their work based on poorly defined or old transferred information from preceding activities. This causes a greater impact on the timing of the project, while the activities are interdependent rather than dependent or sequential.

Other important matters to be considered are the techniques used for shaping a database for storing information at the right place, right time, and right format. There is no doubt that, in each development program, based on its nature, special facets are going to emerge, while the proper accumulation of them constantly improves the knowledge and experience of the involved players. Weak design and poor manufacturing techniques are the other factors that contribute to delay in the projects. The poor design creates changes especially when the detailed design has been carried out. However, sometimes changes are unavoidable, while the customers' needs are changed. In this situation, the impact of 


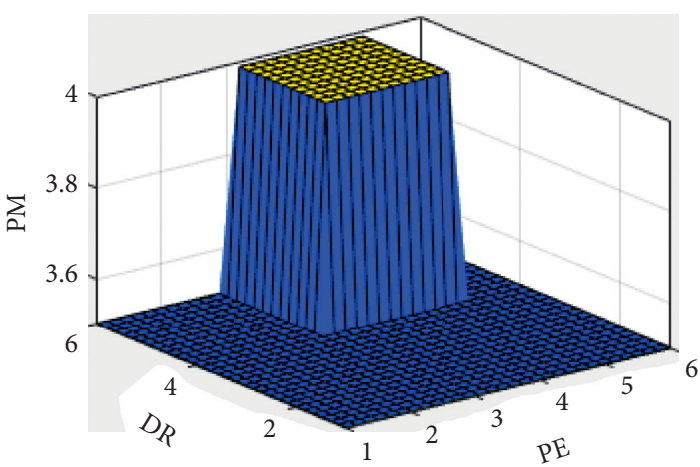

(a)

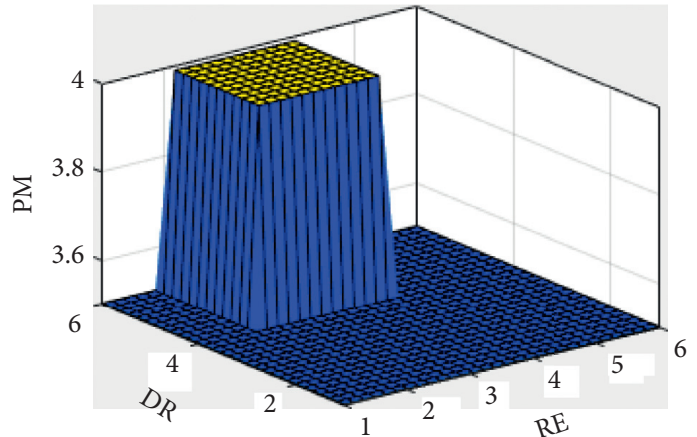

(c)

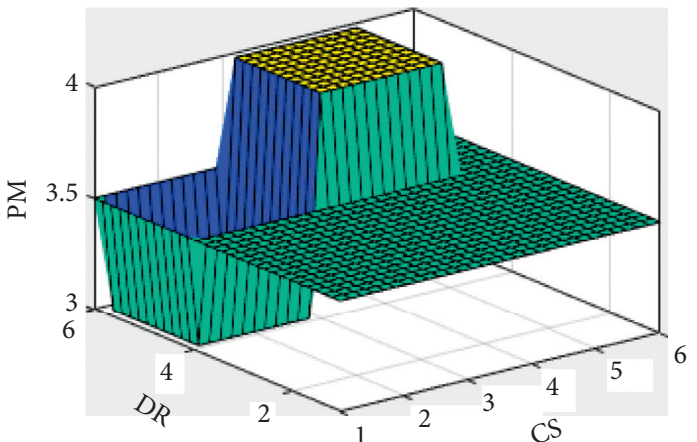

(e)

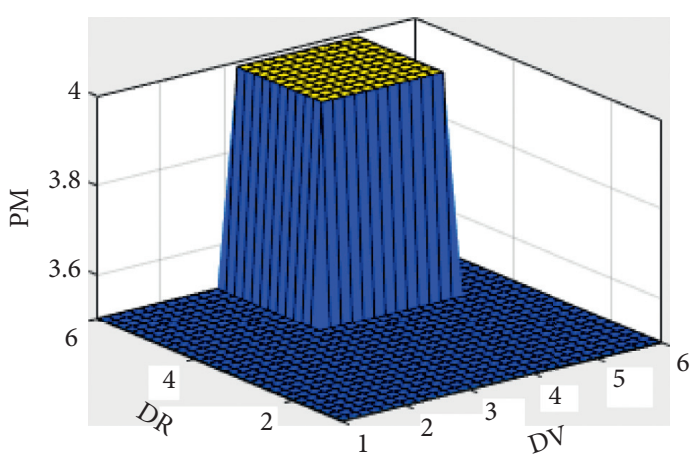

(g)

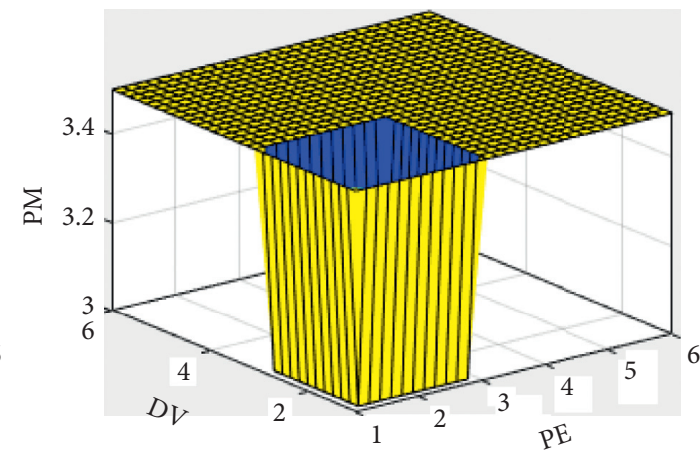

(b)

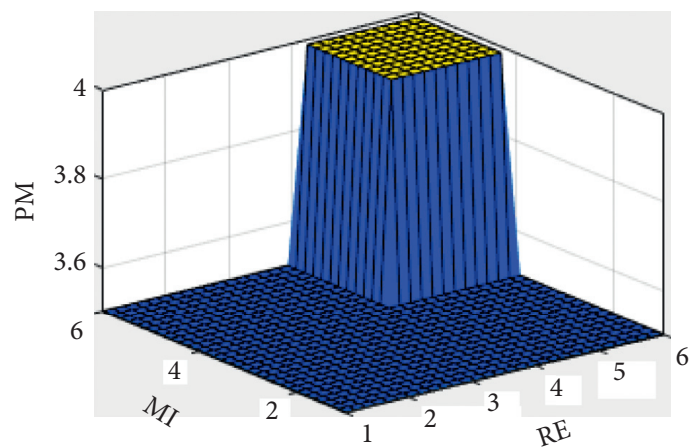

(d)

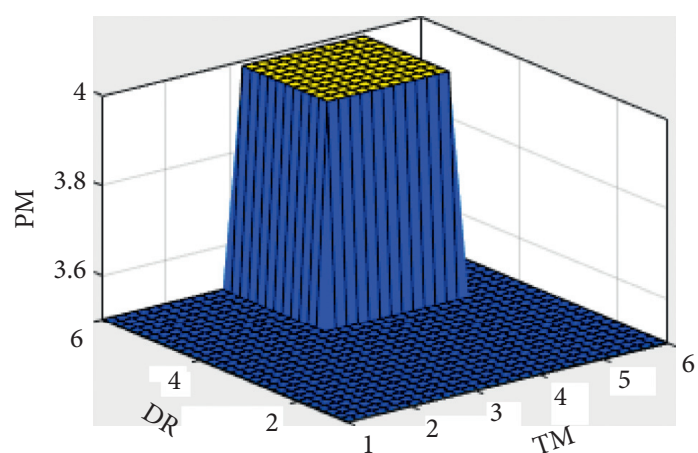

(f)

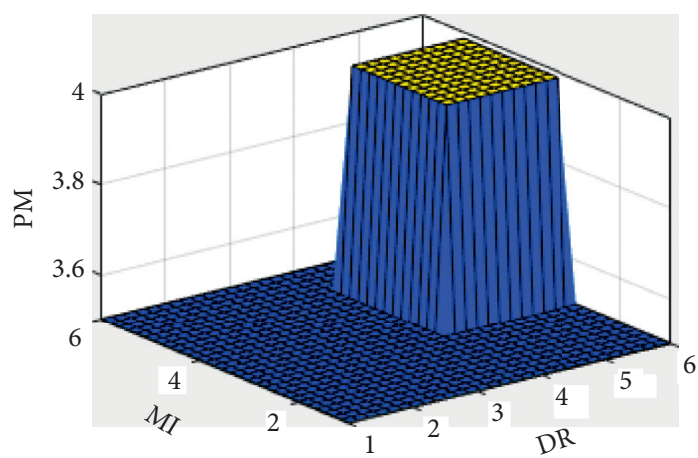

(h)

Figure 9: Illustration of the effects of input variable on the output variable. 
change on different parts of the design should be identified and a trade-off analysis should be made.

\section{Conclusion}

In this study, four main parameters to characterize the process of lead-time reduction, organizational issues, firm resources, used methods and techniques, and performance measuring, in different EPC project-based organizations were considered. Using surveys and questionnaires, by getting help from the experts and managers in project-based organizations and companies, the correlations among them and the lead-time reduction were calculated. The finding was also discussed in the format of lesson-learned and courses of action to improve the development process. Moreover, a mathematical model based on the fuzzy approach to deal with performance measurement parameters is developed. The results of the analysis of the survey show that all the four considered factors are correlated to the lead time and affect the quality perceived by the main client and the cost of the project. Moreover, the results of the proposed fuzzy model illustrated that it may be an effective approach to predict the impact level of the performance measurement by having the levels of its attributes.

As fuzzy models work with predefined rules obtained from experts and managers, having more samples, having more filled surveys, and using more companies active in project-based activities may give better results to analyze the model. Therefore, having wider samples may be considered as a guideline for future studies. Moreover, the proposed mathematical model can be applied to study different parameters such as organizational issues, firm resources, and used methods and techniques based on their subfactors.

\section{Data Availability}

No data were used to support this study.

\section{Conflicts of Interest}

The authors declare that they have no conflicts of interest.

\section{References}

[1] N. F. Dewi, S. M. F. Azam, and S. K. M. Yusof, "Factors influencing the information quality of local government financial statement and financial accountability," Management Science Letters, vol. 9, no. 9, pp. 1373-1384, 2019.

[2] T. J. Marion and S. K. Fixson, "The transformation of the innovation process: how digital tools are changing work, collaboration, and organizations in new product development"," Journal of Product Innovation Management, vol. 38, no. 1, pp. 192-215, 2021.

[3] J. L. Ferreras-Méndez, J. Olmos-Peñuela, A. Salas-Vallina, and J. Alegre, "Entrepreneurial orientation and new product development performance in SMEs: the mediating role of business model innovation," Technovation, vol. 108, Article ID 102325, 2021.

[4] A. A. Alwreikat and H. Rjoub, "Impact of mobile advertising wearout on consumer irritation, perceived intrusiveness, engagement and loyalty: a partial least squares structural equation modelling analysis," South African Journal of Business Management, vol. 51, no. 1, p. 11, 2020.

[5] M. Relich and P. Pawlewski, "A case-based reasoning approach to cost estimation of new product development," Neurocomputing, vol. 272, pp. 40-45, 2018.

[6] A. Alhmoud and H. Rjoub, "Does generation moderate the effect of total Rewards on employee retention? Evidence from Jordan," Sage Open, vol. 10, no. 3, Article ID 2158244020957039, 2020.

[7] N. R. Gunsel, T. Tursoy, and an d H. Rjoub, "An empirical analysis of currency crises, fundamentals and speculative pressure," African Journal of Business Management, vol. 4, no. 6, pp. 972-978, 2010.

[8] A. L. Dias and L. F. Lages, "Measuring market-sensing capabilities for new product development success," Journal of Small Business and Enterprise Development, vol. 28, no. 7, pp. 1012-1034, 2021.

[9] S. M. M. Davoudi, K. Fartash, V. G. Zakirova et al., "Testing the mediating role of open innovation on the relationship between intellectual property rights and organizational performance: a case of science and technology park," Eurasia Journal of Mathematics, Science and Technology Education, vol. 14, no. 4, pp. 1359-1369, 2018.

[10] K. Fartash, S. M. M. Davoudi, T. A. Baklashova et al., "The impact of technology acquisition \& exploitation on organizational innovation and organizational performance in knowledge-intensive organizations," Eurasia Journal of Mathematics, Science and Technology Education, vol. 14, no. 4, pp. 1497-1507, 2018.

[11] Y. Dan, A. A. A. Ahmed, S. Chupradit, P. W. Chupradit, A. A. Nassani, and M. Haffar, "The nexus between the big five personality traits model of the digital economy and blockchain technology influencing organization psychology," Frontiers in Psychology, vol. 12, no. 780527, pp. 1-12, 2021.

[12] J. Ferreira, A. Coelho, and L. Moutinho, "Strategic alliances, exploration and exploitation and their impact on innovation and new product development: the effect of knowledge sharing," Management Decision, vol. 59, no. 3, pp. 524-567, 2021.

[13] P. Manojkumar, M. Suresh, A. A. Ayub Ahmed et al., “A novel home automation distributed server management system using Internet of Things," International Journal of Ambient Energy, pp. 1-6, 2021.

[14] M. Aramand, "Software products and services are high tech? New product development strategy for software products and services," Technovation, vol. 28, no. 3, pp. 154-160, 2008.

[15] T. K. Neogy and A. A. A. Ahmed, "The extent of disclosure of different components of disclosure index: a study on commercial banks in Bangladesh," Global Disclosure of Economics Business, vol. 4, no. 2, pp. 100-110, 2015.

[16] A. A. A. Ahmed, H. Paruchuri, S. Vadlamudi, and A. Ganapathy, "Cryptography in Financial Markets: potential channels for future financial stability," Academy of Accounting and Financial Studies Journal, vol. 25, no. 4, pp. 1-9, 2021.

[17] M. Bahadori, M. Ghasemi, E. Hasanpoor, S. M. Hosseini, and K. Alimohammadzadeh, "The influence of ethical leadership on the organizational commitment in fire organizations," International Journal of Ethics Systems, vol. 37, no. 1, pp. 145-156, 2021.

[18] R. Malekzadeh, G. Abedi, E. Abedini, E. Haghgoshayie, E. Hasanpoor, and M. Ghasemi, "Ethical predictability of patient safety in Iranian hospitals," The International Journal of Risk and Safety in Medicine, vol. 32, no. 1, pp. 51-60, 2021. 
[19] I. M. R. Al-Ameedee and H. O. Abd Alzahrh, "The role of creativity and business performance on crisis management: evidence from Iraqi listed companies," International Journal of Economics and Finance Studies, vol. 13, no. 2, pp. 45-64, 2021.

[20] B. Ponte, J. Costas, J. Puche, R. Pino, and D. de la Fuente, "The value of lead time reduction and stabilization: a comparison between traditional and collaborative supply chains," Transportation Research Part E: Logistics and Transportation Review, vol. 111, pp. 165-185, 2018.

[21] J. W. Strandhagen, L. R. Vallandingham, E. Alfnes, and J. O. Strandhagen, "Operationalizing lean principles for lead time reduction in engineer-to-order (ETO) operations: a case study," IFAC-PapersOnLine, vol. 51, no. 11, pp. 128-133, 2018.

[22] R. Malekzadeh, S. Yaghoubian, E. Hasanpoor, and M. Ghasemi, "Health system responsiveness in Iran: a crosssectional study in hospitals of Mazandaran province," International Journal of Human Rights in Healthcare, 2021.

[23] M. Bahadori, M. Yaghoubi, E. Haghgoshyie, M. Ghasemi, and E. Hasanpoor, 'Patients' and physicians' perspectives and experiences on the quality of medical consultations: a qualitative study," International Journal of Evidence-Based Healthcare, vol. 18, no. 2, pp. 247-255, 2020.

[24] B. Subiyakto and K. Sebastian, "The government reform on healthcare facilities from the standpoint of service quality performance," International Journal of Economics and Finance Studies, vol. 12, no. 1, pp. 16-31, 2020.

[25] L. Van Den Berg and J. Surujlal, "The relationship between coach guidance, feedback, goal setting, support and A longterm development focus of university athletes," International Journal of Social Sciences and Humanity Studies, vol. 12, no. 2, pp. 273-288, 2020.

[26] S. U. Pathiratne, A. Khatibi, and M. G. M. Johar, "CSFs for Six Sigma in service and manufacturing companies: an insight on literature," International Journal of Lean Six Sigma, vol. 9, no. 4, pp. 543-561, 2018.

[27] M. J. F. Seoane, "Employability profiles: the case of a Spanish University," Cuadernos de Economía, vol. 43, no. 123, pp. 341-352, 2020.

[28] A. Z. Putri, "Relationship of company's characteristics and markets power on leverage in Indonesian manufacturing companies," Cuadernos de Economía, vol. 43, no. 123, pp. 401-409, 2020.

[29] M. S. Ab Yajid, S. M. Shukri, and A. Khatibi, "Expansion strategies for achieving competitiveness among airline companies in Malaysian territory," Systematic Reviews in Pharmacy, vol. 11, no. 1, pp. 761-769, 2020.

[30] M. S. Ab Yajid, M. Johar, and S. F. Azam, "Determinants of telecommunication technology adaptation by Malaysian ICT companies," Systematic Reviews in Pharmacy, vol. 11, no. 1, pp. 687-694, 2020.

[31] A. K. Tarofder, S. R. Nikhashemi, S. F. Azam, P. Selvantharan, and A. Haque, "The mediating influence of service failure explanation on customer repurchase intention through customers satisfaction," International Journal of Quality Service Sciences, vol. 8, no. 4, pp. 516-535, 2016.

[32] Y. Wang, S. B. Modi, and T. Schoenherr, "Leveraging sustainable design practices through supplier involvement in new product development: the role of the suppliers' environmental management capability," International Journal of Production Economics, vol. 232, Article ID 107919, 2021.

[33] S. C. Goldt, Implementing Cycle Time Reduction in Product Development, Massachusetts Institute of Technology, Cambridge, Massachusetts, 1995.
[34] M. Ghasemi, M. G. Nejad, and I. Aghaei, "Knowledge management orientation and operational performance relationship in medical tourism (overview of the model performance in the COVID-19 pandemic and post-pandemic era)," Health Services Management Research, vol. 34, no. 4, pp. 208-222, Article ID 0951484820971438, 2021.

[35] S. A. Athari, U. V. Alola, M. Ghasemi, and A. A. Alola, "The (Un) sticky role of exchange and inflation rate in tourism development: insight from the low and high political risk destinations," Current Issues in Tourism, vol. 24, no. 12, pp. 1670-1685, 2021.

[36] M. Ghasemi, M. Ghadiri Nejad, and K. Bagzibagli, "Knowledge management orientation: an innovative perspective to hospital management," Iranian Journal of Public Health, vol. 46, no. 12, pp. 1639-1645, 2017.

[37] M. G. Nejad, S. M. Shavarani, H. Güden, and R. V. Barenji, "Process sequencing for a pick-and-place robot in a real-life flexible robotic cell," International Journal of Advanced Manufacturing Technology, vol. 103, no. 9, pp. 3613-3627, 2019.

[38] M. S. Ab Yajid, “An analysis of the consumer's price and service quality preferences: a case of airline industry in Malaysia," Systematic Reviews in Pharmacy, vol. 11, no. 1, pp. 808-816, 2020.

[39] M. S. Ab Yajid, "Mediating role of organizational culture on the association between business social responsibility and organization performance in Nigeria," Systematic Reviews in Pharmacy, vol. 11, no. 1, pp. 646-653, 2020.

[40] A. A. Aldousari, A. Robertson, M. S. A. Yajid, and Z. U. Ahmed, "Impact of employer branding on organization's performance," Journal of Transnational Management, vol. 22, no. 3, pp. 153-170, 2017.

[41] A. Ahmad, A. Jamaludin, N. S. M. Zuraimi, and M. Valeri, "Visit intention and destination image in post-Covid-19 crisis recovery," Current Issues in Tourism, vol. 24, no. 17, pp. 2392-2397, 2021.

[42] W. Bai, Y. Feng, Y. Yue, and L. Feng, "Organizational structure, cross-functional integration and performance of new product development team," Procedia Engineering, vol. 174, pp. 621-629, 2017.

[43] A. F. Y. B. Jaapar, R. A. A. Helmi, A. Jamal, and M. Aisha, "Employee abuse online reporting application," International Journal of Medical Toxicology Legal Medicine, vol. 23, no. 1and2, pp. 100-104, 2020.

[44] A. Mosbah, M. A. Ali, I. H. Aljubari, and S. R. Sherief, "Migrants in the High-Tech and engineering sectors: an emerging research area," in Proceedings of the 2018 IEEE Conference on Systems, Process and Control (ICSPC), December 2018.

[45] Y. J. Wu and J.-C. Chen, "Stimulating innovation with an innovative curriculum: a curriculum design for a course on new product development," International Journal of Management in Education, vol. 19, no. 3, Article ID 100561, 2021.

[46] Y. Tsang, C. H. Wu, K. Y. Lin, Y. K. Tse, G. T. S. Ho, and C. K. M. Lee, "Unlocking the power of big data analytics in new product development: an intelligent product design framework in the furniture industry," Journal of Manufacturing Systems, 2021.

[47] A. A. M. Alsunki, M. A. Ali, A. A. Jaharadak, and N. M. Tahir, "Framework of software developers engagement antecedents and productivity-A review," in Proceedings of the 2020 16th IEEE International Colloquium on Signal Processing \& Its Applications (CSPA), February 2020. 
[48] A. C. Thornton, S. Donnelly, and B. Ertan, "More than just robust design: why product development organizations still contend with variation and its impact on quality," Research in Engineering Design, vol. 12, no. 3, pp. 127-143, 2000.

[49] N. Ghadirinejad, M. G. Nejad, and N. Alsaadi, "A fuzzy logic model and a neuro-fuzzy system development on supercritical $\mathrm{CO}_{2}$ regeneration of $\mathrm{Ni} / \mathrm{Al}_{2} \mathrm{O}_{3}$ catalysts," Journal of $\mathrm{CO}_{2}$ Utilization, vol. 54, Article ID 101706, 2021.

[50] M. Golabi and M. G. Nejad, "Intelligent and fuzzy UAV transportation applications in aviation 4.0," in Intelligent and Fuzzy Techniques in Aviation 4.0, pp. 431-458, Springer, Heidelberg, Germany, 2022. 